\title{
Insulin-resistance syndrome type A
}

INSERM

\section{Source}

INSERM. (1999). Orphanet: an online rare disease and orphan drug data base. Insulinresistance syndrome type A. ORPHA:2297

Type A insulin-resistance syndrome belongs to the group of extreme insulin-resistance syndromes (which includes leprechaunism, the lipodystrophies, Rabson-Mendenhall syndrome and type B insulin resistance syndrome; see these terms) and is characterized by the triad of hyperinsulinemia, acanthosis nigricans (skin lesions associated with insulin resistance), and signs of hyperandrogenism in females without lipodystrophy and who are not overweight. 